\title{
INFLUENCE OF CONCOMITANT ARTERIAL HYPERTENSION ON ACTIVITY OF INFLAMMATORY PROCESS IN PATIENTS WITH COMMUNITY-ACQUIRED PNEUMONIA
}

\author{
Olha Shtepa \\ Department of Internal medicine 2 \\ SE "Dnipripetrovsk medical academy of Health Ministry of Ukraine" \\ 9 Vernadskogo str., Dnipro, Ukraine, 49044 \\ olgashtepa@meta.ua
}

\begin{abstract}
The aim of the work was to determine the diagnostic value of the markers of surfactant protein D (SP-D) and C-reactive protein (C-RP) in patients with community-acquired pneumonia (CAP) with concomitant arterial hypertension (AH) and its effects on the activity of the inflammatory process.

The study included 79 people. Among them, 63 patients with CAP and 16 healthy individuals who were a control group. Depending on the presence of hypertension, the patients were divided into two groups. The first group included 26 patients with CAP with AH, the second - 37 patients with CAP without AH. All patients were given general-clinical methods of examination, radiography of the chest organs in two projections. Plasma levels of SP-D and C-RP were determined.

Reliable connection $(\mathrm{p}<0.05)$ was determined between the presence of AH and the probability of occurrence of CAP (OR odds ratio 2.27 [95\% CI 1.05-4.94]). The level of SP-D and C-RP in patients with AH on the first day was significantly higher than in healthy subjects $(\mathrm{p}<0.05)$. In patients in the first group, SP-D levels were significantly higher $(\mathrm{p}<0.05)$ for the first, third and ninth day relative to the second group. The existence of a direct tie of average strength between the presence of AH and SP-D ( $R=0.41$, $\mathrm{p}<0.05)$ has been determined. The presence of a direct correlation link of mean strength $(\mathrm{R}=0.38 ; \mathrm{p}<0.05)$ between the $A H$ and the level of C-RP indicates that arterial hypertension in patients with CAP increases the activity of the systemic inflammatory response.

Keywords: community-acquired pneumonia, arterial hypertension, surfactant protein D, C-reactive protein.
\end{abstract}

\section{Introduction}

Community-acquired pneumonia (CAP), as a disease, remains one of the most important unresolved issues in modern pulmonology [1]. Cardiovascular system dysfunction is almost a constant companion of the CAP and develops from the first hours, with blood circulation disturbances often determine the prognosis and the result of the CAP itself. The spectrum of these violations is varied and depends on the severity of the process [2].

The freaquency of arterial hypertension (AH) can reach $63.9 \%$ with the damage to target organs in patients with CAP. Along with this, the development of anemia is accompanied by violations of microcirculation, which occurs in the mechanism of formation of hypertension, factors of non-specific inflammation characterized by an increase in C-reactive protein (C-RP) [3, 4]. Reducing the surfactant protein D (SP-D) may be due to the absorption and destruction of SP-D by the alveolar macrophages, which, due to damage to the pulmonary epithelium and infiltration of capillaries, causes SP-D to leak into the systemic circulation [5]. The presence of SP-D in the systemic circulation can contribute to the development of cardiovascular disease and mortality in patients with CAP, as its role in the development of endothelial dysfunction is known [6]. It is also important that in the vascular wall SP-D can perform the same anti-inflammatory function as in the lungs or vice versa, leading to a pro-inflammatory reaction [7].

Recent studies have revealed several mechanisms for violation or SP-D modifications that contribute to its systemic leakage from the lungs, while the circulatory level SP-D is a promising biomarker to determine the degree of damage to the lung tissue [8,9]. The work performed on mice showed a connection between a decrease in alveolar SP-D levels and an increase in oxidative mechanisms [10, 11]. The SP-D concentration gradient thus allows leakage into the bloodstream SP-D with acute and chronic lung injury, as confirmed in experimental studies in mice [11]. Inter- 
pretation of the quantitative evaluation of SP-D in alveolar fluid and serum in various pulmonary diseases may be a hindrance because anti-SP-D antibodies may have different susceptibilities in the oxidation process [7, 8]. In recent years, it has been shown that SP-D has different antimicrobial and anti-inflammatory effects, affects lipid metabolism and shows pro-inflammatory effects in the walls of vessels, which increases the risk of atherosclerosis. The common polymorphism of SP-D is associated with atherosclerosis and diabetes, as well as metabolic disorders due to its effect on vascular endothelium $[6,12]$. This review summarizes the importance of studying the circulating level of SP-D, the ability to interact in a diagnostic program with already well-known markers of systemic inflammation and the effect or dependence on the presence of comorbidity in patients with CAP in a hospital.

\section{Aim of research}

Determination of the diagnostic value of markers SP-D and C-RP in patients with CAP with concomitant arterial hypertension and its effect on the activity of the inflammatory process.

\section{Materials and methods}

The study included 79 people who were on the treatment in the pulmonologic department of the Mechnikov Regional Clinical Hospital and in the therapeutic department of the City Clinical Hospital No. 6 for the period from 2013 to 2016. Among them, 63 patients with CAP, who were diagnosed with CAP of 2 and 3 clinical groups and 16 healthy individuals, who were the control group.

In order to study the effect of comorbid hypertension on the severity of the inflammatory process, the patients were divided into two groups. To the first group included 26 patients with CAP with $\mathrm{AH}$, the second -- 37 patients with CAP without AH. Duration of hypertension in the first group in $35 \%$ of cases was more than 10 years, in $45 \%$ of cases - from 5 to 10 years and in $20 \%$ of cases - less than 5 years. The average systolic blood pressure level was $145 \pm 2.4 \mathrm{~mm} \mathrm{Hg}$.

Compared to the clinical course, it should be noted that in the first group, the inflammatory process in the lung tissue according to X-ray examination in the form of infiltration was detected on one side in $64 \%$, bilateral - $36 \%$, whereas in the second group, the one-side process was found in $84 \%$, and bilateral at $16 \%$. The course of the disease in patients with concomitant hypertension was characterized by a longer period of the disease.

Criteria for inclusion of patients in the study: age 18 and over; the presence of clinical and radiological signs of the inflammatory process in the lungs in patients with CAP; the presence of concomitant arterial hypertension in patients with CAP. Criteria for exclusion of patients from the study: refusal of the patient to participate in the study; the duration of antibiotic therapy for more than 24 hours; use in the therapeutic program for any nosology over the past three months of antibacterial treatment; the presence of a disease for tuberculosis, malignant neoplasms, AIDS, alcohol or drug addiction; the presence of any other severe pulmonologic pathology.

The average age of patients in the first group was $52 \pm 2.6$ years, among them $52 \%$ of men and $48 \%$ of women. The average age of patients in the second group was $45 \pm 3.1$ years, among them $46 \%$ men and $54 \%$ women. In patients with the first group in $62 \%$ of cases the body temperature reached low-grade markers, $38 \%$ - febrile ones, whereas in patients of the second group the distribution of subfebrile and febrile levels in the percentage ratio was 49 to 51, respectively. The average level of leukocytes in the first group was $14.7 \pm 4.9 \times 109 / \mathrm{ml}$, in the second $-13.8 \pm$ $\pm 4.9109 / \mathrm{ml}$. The average level of erythrocyte sedimentation rate was $32.6 \pm 3.6 \mathrm{~mm} / \mathrm{g}$ and $27.4 \pm$ $\pm 4.4 \mathrm{~mm} / \mathrm{g}$ respectively in the first and second groups.

At the research stage, evaluation of the general condition and clinical symptoms in patients with infectious neuropathy was conducted according to a single scheme: for 1-2 days, 3-4 and 9-10 days from the moment of admission to the department. All patients were given general-clinical methods of examination, radiography of the chest organs in two projections.

The plasma level of SP-D was determined by immuno-enzymatic analysis using Hycult Biotech (the Netherlands) reagents according to the manufacturer's protocol. The plasma level of C-RP was determined using the IT-CRP 2* 1S reagents (Lachema, Slovakia) by immunoturbimetric method using the Microlab-200 photometer according to the protocols of the manufacturer. 
The obtained results were analyzed using the Microsoft Office Excel program and the STATISTICA 6.1 software (StatSoftInc., Serial number AGAR909E415822FA) using descriptive methods (the description of the central tendency of quantitative attributes was performed with normal distribution in the form of an average arithmetic and standard error $\mathrm{M} \pm \mathrm{m}$; in the opposite case in the form of median and interquat-wise Me [25-75\%], $95 \%$ confidence interval (CI) was calculated to determine the range of indicators in the population, and analytical statistics methods were used References [13].

\section{Results of the research}

In the course of the study, the results of simple logistic regression analysis revealed a reliable connection $(\mathrm{p}<0.05)$ between the presence of hypertension and the probability of the occurrence of CAP (OR - odds ratio 2.27 [95 \% CI 1.05 - 4.94]). There was no statistically significant relationship between the presence of hypertension and the severity of CAP $(p>0.05)$.

According to the rank correlation analysis, the existence of a direct correlation between the level of SP-D and the presence of hypertension in patients in the first group was determined $(\mathrm{R}=0.41, \mathrm{p}<0.05)$.

It was also confirmed that there is a direct correlation connection of average strength $(\mathrm{R}=0.38 ; \mathrm{p}<0.05)$ between the comorbid AH and the C-RP level, based on the Spirman rank correlation coefficient.

In the conditions of the study, the correlation analysis of the results did not reveal a probable relationship between the plasma levels of C-RP and SP-D in patients in the first group $(\mathrm{R}=0.16$, $\mathrm{p}>0.05)$ and the second group $(\mathrm{R}=0.24, \mathrm{p}>0.05)$.

Results of measurements of plasma level of C-reactive protein in patients of the first and second groups are presented in Table 1.

The level of C-RP was significantly higher in patients with both groups in healthy subjects $(p<0.001)$ and on average increased to $73.22-94.70 \mathrm{mg} / 1$, while the maximum values reached $405 \mathrm{mg} / \mathrm{l}$.

As a result of the analysis, it was determined that the level of C-RP in patients with CAP on the first day was significantly higher than that of healthy subjects $(\mathrm{p}<0.05)$, and subsequently to the third day it gradually decreased in both groups $(\mathrm{p}<0.05)$, compared with the previous indicators and reached the normal values for the ninth day and did not differ from the control group ( $p>0.05$ ).

In the process of comparing the data obtained from the first and second groups, it was determined that the level of C-RP in patients with concomitant hypertension on the first day was characterized by the presence of statistical tendency to higher values $(p=0.067)$ in patients in the first group by $23 \%$, the third day, the level C-RP decreased and was significantly higher $(\mathrm{p}<0.05)$ in patients in the first group by $44 \%$. There was a significant difference between the C-RP indexes in the patients in the first group and the control group $(\mathrm{p}<0.05)$ in the ninth day, while the second group's statistical significance was not statistically significant in relation to the control group. The C-RP indexes of the first and second groups had a difference of $43 \%$ for the ninth day.

Table 1

Change in the average levels of C-RP in the course of the inflammatory process in patients with CAP in comparison with the control group

\begin{tabular}{|c|c|c|c|}
\hline Groups & $\begin{array}{l}\text { C-RP, the first day } \\
\text { Me }[25-75 \%] \mathrm{mg} / \mathrm{l}\end{array}$ & $\begin{array}{l}\text { C-RP, the third day } \\
\text { Me }[25-75 \%] \mathrm{mg} / \mathrm{l}\end{array}$ & $\begin{array}{l}\text { C-RP, the ninth day } \\
\text { Me }[25-75 \%] \mathrm{mg} / \mathrm{l}\end{array}$ \\
\hline $\begin{array}{c}\text { First group } \\
\text { (CAP with } \mathrm{AH}), \mathrm{n}=26\end{array}$ & $\begin{array}{c}94.70 \\
{[58.44-171.6]^{\text {\#\# }}}\end{array}$ & $\begin{array}{c}48.42 \\
{[15.3-132.95]^{* \text { o\# }}}\end{array}$ & $\begin{array}{c}8.97 \\
{[6.31-9.35]^{* \circ \#}}\end{array}$ \\
\hline $\begin{array}{c}\text { Second group } \\
(\mathrm{CAP} \text { without } \mathrm{AH}), \mathrm{n}=37\end{array}$ & $\begin{array}{c}73.22 \\
{[34.81-199.52]^{\circ}}\end{array}$ & $\begin{array}{c}27.04 \\
{[16.07-102.61]^{\circ *}}\end{array}$ & $\begin{array}{c}5.12 \\
{[4.1-6.25]^{*}}\end{array}$ \\
\hline Control group & & $4.47[3.28-5.82]$ & \\
\hline
\end{tabular}

Note: ${ }^{*}-p<0.05$ according to the Wilcoxon criterion relative to the foreground value in each group separately; ${ }^{\circ}-p<0.05$ according to the Mann-Whitney criterion relative to the control group; $\#-p<0.05$ according to the Mann-Whitney criterion between the groups depending on the presence of hypertension 
Changes in SP-D levels during the course of the process obtained in patients in our study in the process of assessing the severity of inflammation are presented in Table 2.

The level of SP-D in patients with the first and second groups for the first day of the statistical data was significantly higher than the control group $(\mathrm{p}<0.002)$. On average, the values of SP-D in both groups were determined within the range 429.119-608.708 $\mathrm{ng} / \mathrm{ml}$ for the first day and were significantly higher in the first group $(\mathrm{p}<0.05)$. The maximum values of SP-D in patients reached $731.261-897.405 \mathrm{ng} / \mathrm{ml}$ and were determined mainly for bilateral lung injury.

\section{Table 2}

Change in the average levels of SP-D in the course of the inflammatory process in patients with CAP in comparison with the control group

\begin{tabular}{|c|c|c|c|}
\hline Groups & $\begin{array}{l}\text { SP-D, the first day } \\
\text { Me }[25-75 \%] \mathrm{ng} / \mathrm{ml}\end{array}$ & $\begin{array}{l}\text { SP-D, the third day } \\
\text { Me }[25-75 \%] \mathrm{ng} / \mathrm{ml}\end{array}$ & $\begin{array}{l}\text { SP-D, the ninth day } \\
\text { Me }[25-75 \%] \mathrm{ng} / \mathrm{ml}\end{array}$ \\
\hline $\begin{array}{c}\text { First group } \\
(\mathrm{CAP} \text { with } \mathrm{AH}), \mathrm{n}=26\end{array}$ & $\begin{array}{c}608.708 \\
{[532.000-663.51]^{\circ \wedge}}\end{array}$ & $\begin{array}{c}788.821 \\
{[695.617-807.681]^{* \circ}}\end{array}$ & $\begin{array}{c}373.494 \\
{[250.329-491.36]^{* \circ \wedge}}\end{array}$ \\
\hline $\begin{array}{c}\text { Second group } \\
\text { (CAP without } \mathrm{AH}), \mathrm{n}=37\end{array}$ & $\begin{array}{c}429.119 \\
{[326.851-471.083]^{\circ \wedge}}\end{array}$ & $\begin{array}{c}582.144 \\
{[473.602-622.831]^{* \circ}}\end{array}$ & $\begin{array}{c}279.362 \\
{[194.268-354.423]^{* \wedge}}\end{array}$ \\
\hline Control group & & $238.050[144.736-372.132]$ & \\
\hline
\end{tabular}

In the period from the first to the third day, SP-D indices increased, they were significantly higher $(p<0.05)$ relative to the SP-D index of the first day of both groups and the control group $(p<0.005)$. From the third to the ninth day marker values gradually decreased, statistically the data were significantly lower than the previous values $(\mathrm{p}<0.001)$.

However, the data obtained in the first group were significantly higher $(p<0.05)$ for the control group and SP-D indicators of the second group.

Based on the results obtained, the average SP-D values for the first group with concomitant hypertension were $608.708 \mathrm{ng} / \mathrm{ml}$ and were significantly higher $(\mathrm{p}<0.05)$ for the mean of patients in the second group - $429.119 \mathrm{ng} / \mathrm{ml}$. For the third day, there was no statistic difference between the mean values of SP-D in both groups, however, there was a tendency $(\mathrm{p}=0.059)$ to higher values in patients with the first $(788.821 \mathrm{ng} / \mathrm{ml})$ and the second group $(582.144 \mathrm{ng} / \mathrm{ml})$, respectively. On the ninth day, the indicators gradually approached the values of the control group, but the level of SP-D was significantly higher $(\mathrm{p}<0.05)$ in patients in the first group $(373.494 \mathrm{ng} / \mathrm{ml})$ relative to the second group $(279.362 \mathrm{ng} / \mathrm{ml})$ and statistically different from the control group $(\mathrm{p}<0.05)$. There was no statistically significant difference between the level of SP-D in patients with the second group and the control group $(\mathrm{p}<0.05)$.

\section{Discussion of the results}

Specific pulmonary biomarkers that would be available and could be used for diagnosis, assessment of the course of the infectious process, and the effectiveness of the proposed therapeutic strategies are the aims of many studies [14]. To solve the problems, an analysis of the effectiveness of the use of markers in patients with CAP was performed, depending on the presence of hypertension in terms of comparison with the control group. In the problems of modern medicine, concomitant hypertension in patients with CAP increases the frequency of complications 2.5 times, more than three times the rate of development of pleurisy, lengthens the duration of pulmonary infiltration [15].

For patients with CAP is characteristic an increase in C-RP and its subsequent reduction in the treatment [16], as well as the marker helps in diagnostic determination of the sharpening of the chronic process and the direct presence of the acute inflammatory process of the lungs [17]. However, in both cases, the C-RP level after the therapeutic program is not statistically different 
from that of the control group, which corresponds to the data obtained in our study. The presence of concomitant hypertension increases the activity of the systemic inflammatory response. This is confirmed by the results of the correlation analysis, according to which, there is a direct average strength of the relationship between the presence of hypertension and the level of C-RP. Patients in the first group were characterized by significantly higher levels of C-RP $(p<0.05)$. Increased levels of C-RP in patients with cardiac pathology are associated with changes in vascular stiffness, atherosclerosis and the development of damage to target organs and increased cardiovascular manifestations [18].

To determine the effect of hypertension on the activity of the inflammatory process and damage to the lung tissue, SP-D levels were studied in patients of both groups at the first, third and ninth day. Thus, in patients with the first group in all three observation points, the data obtained were higher relative to the levels of SP-D of the second group, which is related to the influence of hypertension as a factor that characterizes the higher severity of the systemic and local inflammatory response during acute processes, defining injuries pulmonary tissue [19]. The study by Grith L Sorensen and co-authors showed the presence of SP-D in endothelial cells and its involvement in modulating the local inflammatory response [20], which in turn indicates the feedback of the effect of the development of the process of inflammation in the lungs caused by bacterial agents [21] on the possible complications of concomitant arterial hypertension.

The presence of comorbid hypertension in patients with CAP is accompanied by an increase in the level of SP-D in the bloodstream, which for the ninth day is characterized by significantly higher levels of SP-D $(\mathrm{p}<0.05)$ in patients with CAP. Higher SP-D rates were also determined in patients with multiple lesion of the lung on the one hand, indicating a marked increase in the area of lung tissue damage and bacterial infiltration and the relationship between pathological changes in the body in which the violation occurs as a consequence of primary changes in their own turn, reinforce each other [22].

Thus, the obtained data indicate that SP-D is capable of displaying the activity of inflammation and the severity of the disease [23], to increase its circulating level in the bloodstream during the period of the inflammatory process of the lung and at the same time increase the risk of complication of the course of hypertension that in its queue in the future requires the search for additional possibilities for a rapid decrease in the level of circulating SP-D in the treatment of infectious processes of the lung.

When discussing reports of SP-D genetic associations with a significant disease list [23, 24] and the clinical utility of circulating SP-D for prediction of respiratory diseases [24], it should be noted that the current study has a further direction for its development. Prospective studies consider the development of SP-D therapy [24], and the open question remains about the possibility of influencing the pathogenetic component of the inflammatory process in the treatment program [25].

\section{Conclusions}

1. Relative connection $(\mathrm{p}<0.05)$ between the presence of arterial hypertension and the probability of occurrence of community-acquired pneumonia (OR - odds ratio 2.27 [95 \% CI 1.05 4.94]) was determined based on the results of simple logistic regression analysis.

2. Concomitant arterial hypertension in patients with community-acquired pneumonia increases the activity of the systemic inflammatory response, which is confirmed by the results of the correlation analysis of the $\mathrm{C}$-RP (Spearman rank correlation coefficient $\mathrm{R}=0.38 ; \mathrm{p}<0.05$ ).

3. The existence of a direct link of average strength between the presence of arterial hypertension and the level of surfactant protein $\mathrm{D}(\mathrm{R}=0.41, \mathrm{p}<0.05)$, which characterizes a higher expressiveness of the local inflammatory response during acute processes, reflecting damage to the pulmonary tissue.

\section{References}

[1] Mandell, L. A., Wunderink, R. G., Anzueto, A., Bartlett, J. G., Campbell, G. D., Dean, N. C. et. al. (2007). Infectious Diseases Society of America/American Thoracic Society Consensus Guidelines on 
the Management of Community-Acquired Pneumonia in Adults. Clinical Infectious Diseases, 44, 27-72. doi: $10.1086 / 511159$

[2] Corrales-Medina, V. F., Musher, D. M., Wells, G. A., Chirinos, J. A., Chen, L., Fine, M. J. (2012). Cardiac Complications in Patients With Community-Acquired Pneumonia: Incidence, Timing, Risk Factors, and Association With Short-Term Mortality. Circulation, 125 (6), 773-781. doi: 10.1161/ circulationaha.111.040766

[3] Dotsenko, N. Ya., Boev, S. S., Shekhunova, Y. A. et. al. (2015). Difficulties and frequent errors in the management of patients with arterial hypertension. Arterialnaya gipertenziya, 3 (41), 30-34.

[4] Perry, T. W., Pugh, M. J. V., Waterer, G. W., Nakashima, B., Orihuela, C. J., Copeland, L. A. et. al. (2011). Incidence of Cardiovascular Events After Hospital Admission for Pneumonia. The American Journal of Medicine, 124 (3), 244-251. doi: 10.1016/j.amjmed.2010.11.014

[5] Gargiulo, P., Banfi, C., Ghilardi, S., Magrì, D., Giovannardi, M., Bonomi, A. et. al. (2014). Surfactant-Derived Proteins as Markers of Alveolar Membrane Damage in Heart Failure. PLoS ONE, 9 (12), e115030. doi: 10.1371/journal.pone.0115030

[6] Sin, D. D., Wu, L., Man, S. F. (2005). The relationship between reduced lung function and cardiovascular mortality: a population-based study and a systematic review of the literature. Chest, 127 (6), 1952-1959. doi: 10.1378/chest.127.6.1952

[7] Atochina-Vasserman, E. N. (2012). S-nitrosylation of surfactant protein D as a modulator of pulmonary inflammation. Biochimica et Biophysica Acta (BBA) - General Subjects, 1820 (6), 763-769. doi: 10.1016/j.bbagen.2011.12.006

[8] Atochina-Vasserman, E. N., Winkler, C., Abramova, H., Schaumann, F., Krug, N., Gow, A. J. et. al. (2011). Segmental Allergen Challenge Alters Multimeric Structure and Function of Surfactant Protein D in Humans. American Journal of Respiratory and Critical Care Medicine, 183 (7), 856-864. doi: 10.1164/ rccm.201004-0654oc

[9] Pertseva, T. O., Kireyeva, T. V., Shtepa O. O. (2015). The influence of comorbid pathology on expressiveness of inflammatory process in patients with lower respiratory tract infactions. Zaporozhye medical journal, 4 (91), 21-25. doi: 10.14739/2310-1210.2015.4.50306

[10] Sorensen, G. L., Hjelmborg, J. V. B., Leth-Larsen, R., Schmidt, V., Fenger, M., Poulain, F. et. al. (2006). Surfactant Protein D of the Innate Immune Defence is Inversely Associated with Human Obesity and SP-D Deficiency Infers Increased Body Weight in Mice. Scandinavian Journal of Immunology, 64 (6), 633-638. doi: 10.1111/j.1365-3083.2006.01853.x

[11] Schneider, J. P., Arkenau, M., Knudsen, L., Wedekind, D., Ochs, M. (2017). Lung remodeling in aging surfactant protein D deficient mice. Annals of Anatomy - Anatomischer Anzeiger, 211, 158-175. doi: 10.1016/j.aanat.2017.01.013

[12] Hoegh, S. V., Sorensen, G. L., Tornoe, I., Lottenburger, T., Ytting, H., Nielsen, H. J. et. al. (2010). Long-term stability and circadian variation in circulating levels of surfactant protein D. Immunobiology, 215 (4), 314-320. doi: 10.1016/j.imbio.2009.05.001

[13] Rebrova, O. Yu. (2002). Statistical analysis of medical data. The use of the application package statistics. Moscow: MediaSphere, 312.

[14] Pertseva, T. O., Kireieva, T. V., Shtepa, O. O. (2014). Surfactant Protein D and C-Reactive Protein in patients with lower respiratory tract infections. The Pharma Innovation Journal, 3 (9), 27-31.

[15] Hill, J., Heslop, C., Man, S. F. P., Frohlich, J., Connett, J. E., Anthonisen, N. R. et. al. (2011). Circulating surfactant protein-D and the risk of cardiovascular morbidity and mortality. European Heart Journal, 32 (15), 1918-1925. doi: 10.1093/eurheartj/ehr124

[16] Pertseva, T. et. al. (2014). Surfactant protein D (SPD) and C-reactive protein (CRP) levels in patients (pts) with community acquired pneumonia (CAP) during the treatment program. European Respiratory Journal, 44 (58), 3645.

[17] Pertseva, T. et al. (2014). The difference between surfactant protein D (SPD) and C-reactive protein (CRP) levels in patient (pts) with chronic obstructive pulmonary disease acute exacerbations (AE COPD) and community acquired pneumonia (CAP). European respiratory society, 3576. 
[18] Ware, L. B., Koyama, T., Billheimer, D. D., Wu, W., Bernard, G. R., Thompson, B. T. et. al. (2010). Prognostic and Pathogenetic Value of Combining Clinical and Biochemical Indices in Patients With Acute Lung Injury. Chest, 137 (2), 288-296. doi: 10.1378/chest.09-1484

[19] Kalmatov, R. K., Zholdoshev, S. T., Karymova, N. A. (2015). Pathogenetic role of surfactant SP-D protein in diseases of the lungs and respiratory tract. Fundamentalnyie issledovaniya, 1, $1591-1595$.

[20] Sorensen, G. L. (2018). Surfactant Protein D in Respiratory and Non-Respiratory Diseases. Frontiers in Medicine, 5, 1-37. doi: 10.3389/fmed.2018.00018

[21] Shtepa, O. A. (2015). Meaning of surfactant protein D as a marker of pathogenic microorganisms and the degree of damage of the lung tissue. Eksperementalna i klinichna medytsyna, $3(68), 68-72$.

[22] Gaunsbaek, M. Q., Rasmussen, K. J., Beers, M. F., Atochina-Vasserman, E. N., Hansen, S. (2013). Lung Surfactant Protein D (SP-D) Response and Regulation During Acute and Chronic Lung Injury. Lung, 191 (3), 295-303. doi: 10.1007/s00408-013-9452-x

[23] Hartl, D., Griese, M. (2006). Surfactant protein D in human lung diseases. European Journal of Clinical Investigation, 36 (6), 423-435. doi: 10.1111/j.1365-2362.2006.01648.x

[24] Leth-Larsen, R., Nordenbaek, C., Tornoe, I., Moeller, V., Schlosser, A., Koch, C. et. al. (2003). Surfactant protein D (SP-D) serum levels in patients with community-acquired pneumonia Clinical Immunology, 108 (1), 29-37. doi: 10.1016/s1521-6616(03)00042-1

[25] Mandal, P., Chalmers, J. D., Choudhury, G., Akram, A. R., Hill, A. T. (2011). Vascular complications are associated with poor outcome in community-acquired pneumonia. QJM, 104 (6), 489-495. doi: 10.1093/qjmed/hcq247 